\title{
Internação involuntária para dependente químico
}

\author{
Involuntary hospitalization for drug addicts \\ Eduardo Henrique Teixeira' \\ hitp://orid.org/0000-0003-1376-5080 \\ Thaís Cristina Faria Pacheco ${ }^{2}$ \\ hittp://orid.org/0000-0002-2624-1713 \\ Hadassa Louback Paranhos ${ }^{2}$ \\ https://orid.org/0000-0001-7588-8794 \\ Nayane Almeida Luiz² \\ https://orid.org/0000-0002-22255-9832 \\ Carina Zuini Pereira ${ }^{3}$ \\ https://orcid.org/0000-0003-3064-407X
}

\section{SR. EDITOR,}

Dependentes químicos tendem a recusar tratamento por negação de sua doença, desesperança ou visão negativa do tratamento, mesmo cientes da gravidade. Em alguns casos, a internação involuntária pode ser uma das poucas ferramentas para garantir ainda a integridade e a saúde do paciente?.

Na Europa, o modelo de tratamento psiquiátrico involuntário varia muito entre os países, sem padronização e ainda em discussão na União Europeia ${ }^{2}$. Nos Estados Unidos, a internação involuntária deve preencher dois critérios: perigo iminente e completa incapacidade de exercer o autocuidado, contudo ainda sem consenso nacional e com muitas diferenças entre os estados americanos ${ }^{3}$.

No Brasil, a Lei no 10.216/2001 considera três tipos de internação psiquiátrica: voluntária (com o consentimento do paciente); involuntária (sem o consentimento); compulsória (determinada pela justiça).

Considerando que no Brasil o uso de drogas tem aumentado nos últimos anos, constituindo um sério problema de saúde pública ${ }^{4}$, e que a internação involuntária, apesar de ainda controversa, pode ser a última possiblidade de intervenção terapêutica para determinados casos, relatamos abaixo um caso que recebeu essa abordagem.

Trata-se de J. B., 36 anos, sexo masculino, dependente de drogas, F19.2, com fracasso recorrente dos tratamentos prévios e grave prejuízo psicossocial. A internação involuntária foi solicitada pela família após o paciente passar longo período dormindo em via pública. A internação foi realizada em enfermaria psiquiátrica de hospital geral com abordagem multidisciplinar.

O paciente era totalmente contra sua internação e nos primeiros dias apresentava risco de fuga e agressividade. Sentia-se injustiçado e traído pela família. Após a terceira semana, apresentava-se mais ajustado ao projeto terapêutico e já manifestava concordância parcial em relação à internação. Recebeu alta após 45 dias com melhora do insight, reconhecimento da gravidade e da necessidade de internação. Após seis meses, como parte de um estudo

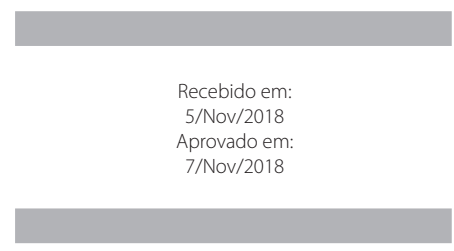

DOI: $10.1590 / 0047-2085000000226$

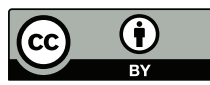

1 Pontifícia Universidade Católica de Campinas (PUC-Campinas), Faculdade de Medicina, Departamento de Psiquiatria, Campinas, SP, Brasil. 2 Pontifícia Universidade Católica de Campinas (PUC-Campinas), Faculdade de Medicina, modalidade FAPIC-Reitoria, Campinas, SP, Brasil. 3 Pontifícia Universidade Católica de Campinas (PUC-Campinas), Faculdade de Medicina, Campinas, SP, Brasil.

Grupo de pesquisa: Diagnóstico e tratamento das doenças e agravos à saúde (CNPQ: psiquiatria).

Linha de pesquisa: Análise do perfil de pacientes usuários de drogas ilícitas, adultos e adolescentes e o impacto das diferentes internações: voluntária, involuntária ou compulsória.

Endereço para correspondência: Eduardo Henrique Teixeira

Rua Paulo Cezar Diniz, 39, sala 112, Alto Taquaral

13087-757 - Campinas, SP, Brasil

Telefone: +55 (19) 3756-1081

E-mail: eduardo.psiquiatra@icloud.com 
prospectivo mais amplo, foi feito contato por telefone e o paciente encontrava-se ainda em abstinência e dizia ser grato pelo tratamento. Manifestava concordância em relação à internação involuntária, mesmo tendo sido contrário no início.

Entendemos que a autonomia é um dos pilares da atuação ética na assistência à saúde, contudo a capacidade de decidir do indivíduo pode estar seriamente comprometida em alguns casos. Apesar de polêmica, a internação involuntária pode ser uma das últimas ferramentas para garantir a integridade e a saúde do paciente. Soma-se a isso o aumento dos casos de dependência que seguem crescendo em nosso país ${ }^{4}$.

Deve-se ficar atento a situações abusivas, negligência, inclusive pela possibilidade de ocorrência de experiências traumáticas, com consequências não desejáveis, como a recusa do paciente em procurar serviço psiquiátrico no futuro ${ }^{5}$.

O caso apresentado permitiu reconhecer que alguns pacientes podem, sim, ser beneficiados pela internação involuntária. O resultado terapêutico foi positivo e o paciente pôde reconhecer, após um período de abstinência, os benefícios de ter sido internado em uma época em que sua vontade e autonomia estavam seriamente comprometidas.
Essa resposta clínica e a mudança na percepção podem servir de alguma forma como embasamento nas discussões éticas sobre autonomia e direitos do paciente envolvendo a internação involuntária'.

\section{REFERÊNCIAS}

1. Opsal A, Kristensen Ø, Larsen TK, Syversen G, Rudshaug BEA, Gerdner A, et al. Factors associated with involuntary admissions among patients with substance use disorders and comorbidity: A cross-sectional study. BMC Health Serv Res. 2013;13.57.

2. Raboch J, Kališová L, Nawka A, Kitzlerová E, Onchev G, Karastergiou A, et al. Use of Coercive Measures During Involuntary Hospitalization: Findings From Ten European Countries. Psychiatr Serv. 2010;61(10):1012-7.

3. Craw J, Compton MT. Characteristics associated with involuntary versus voluntary legal status at admission and discharge among psychiatric inpatients. Soc Psychiatry Psychiatr Epidemiol. 2006;41(12):981-8.

4. Laranjeira R, Madruga CS, Pinsky I, Caetano R, Mitsuhiro SS, Madruga CS, et al. II Levantamento Nacional de Álcool e Drogas (LENAD) - 2012. São Paulo: Instituto Nacional de Políticas Públicas do Álcool e Outras Drogas (INPAD), Universidade Federal de São Paulo (Unifesp); 2014.

5. Zhang S, Mellsop G, BrinkJ, Wang X. Involuntary admission and treatment of patients with mental disorder. Neurosci Bull. 2015;31(1):99-112. 